\title{
The effect of gender on the early results of coronary artery bypass surgery in the younger patients' group
}

\author{
O efeito do gênero sobre os resultados iniciais da cirurgia de revascularização do miocárdio em grupo \\ de pacientes mais jovens
}

\author{
Hasan Uncu' 1 MD; Mehmet Acipayam², MD; Levent Altinay ${ }^{2}$, MD; Pinar Doğan ${ }^{1}$, MD; Isil Davarc1², \\ MD; İbrahim Özsöyler ${ }^{1}$, MD
}

\section{Abstract}

Introduction: In this retrospective study, we aimed to determine the risk factors for coronary artery bypass surgery in patients under 45 years of age, and evaluate the early postoperative results and the effect of gender.

Methods: A total of 324 patients under 45 years of age who undergone on-pump coronary artery bypass surgery between April 12, 2004 and January 10, 2012 were included to the study. Patients divided into groups as follows: Group 1 consisted of 269 males (mean age 41.3), Group 2 consisted of 55 females (mean age 41.6). Preoperative risk factors, intraoperative and postoperative data and early mortality rates of the groups were compared.

Results: Smoking rate was significantly higher in Group 1. Diabetes mellitus incidence and body mass index were significantly higher in Group 2 ( $P$ values $P=0.01 ; P=0.0001$; $P=0.04$ respectively). The aortic cross-clamping and cardiopulmonary bypass time and number of grafts per patient were significantly higher in Group 1 ( $P$ values $P=0.04$; $P=0.04 ; P=0.002$ respectively). There were no deaths in either group.

Conclusion: We found that gender has no effect on early mortality rates of the coronary bypass surgery patients under 45 years.

Descriptors: Cardiopulmonary Bypass. Coronary Artery Bypass. Education, Medical.

${ }^{1}$ Adana Numune Training and Research Hospital Department of Cardiovascular Surgery, Adana, Turkey.

${ }^{2}$ Mustafa Kemal University School Of Medicine, Department of Cardiovascular Surgery, Zülüflühan Köyü, Antakya, Hatay, Turkey.

This study was carried out at Mustafa Kemal University School Of Medicine, Department of Anesthesiology, Antakya, Hatay, Turkey.

\section{Resumo}

Introdução: Este estudo retrospectivo teve como objetivo determinar os fatores de risco para cirurgia de revascularização do miocárdio em pacientes com menos de 45 anos de idade e avaliar os resultados pós-operatórios precoces e o efeito do gênero.

Métodos: Um total de 324 pacientes com menos de 45 anos de idade, que submeteram à cirurgia de revascularização miocárdica entre 12 de abril de 2004 e 10 de janeiro de 2012 foram incluídos no estudo. Os pacientes divididos em dois grupos: Grupo 1, composto por 269 homens (idade média 41,3 anos), Grupo 2, composto por 55 mulheres (idade média 41,6 anos). Fatores de risco pré-operatórios, dados intraoperatórios e pós-operatórios e mortalidade precoce dos grupos foram comparados.

Resultados: A taxa de tabagismo foi significativamente maior no grupo 1. Incidência de diabetes mellitus e massa corporal foram significativamente maiores no grupo 2 (valor de $P: P=0,01$, $P=0,0001, P=0,04$, respectivamente). O pinçamento aórtico e tempo de circulação extracorpórea e número de enxertos por paciente foi significativamente maior no grupo 1 (valor de $P$ : $P=0,04, P=0,04, P=0,002$, respectivamente). Não ocorreram mortes em ambos os grupos.

Conclusão: O gênero não tem efeito sobre as taxas de mortalidade precoce dos pacientes de cirurgia de revascularização do miocárdio com menos de 45 anos.

Descritores: Ponte Cardiopulmonar. Ponte de Artéria Coronária. Educação Médica.

Correspondence address:

Isil Davarc1

Mustafa Kemal University School Of Medicine, Department of Anesthesiology Zülüflühan Köyü, 31000, Antakya, Hatay, Turkey

E-mail: sildavarci@gmail.com 


\begin{tabular}{|ll|}
\hline Abbreviations, acronyms \& symbols \\
\hline ACC & Aortic cross-clamping \\
BMI & Levels, body mass index \\
CABG & Coronary artery bypass graft \\
CAD & Atherosclerotic coronary artery disease \\
COPD & Chronic obstructive pulmonary disease \\
CPB & Cardiopulmonary bypass \\
DM & Diabetes mellitus \\
HT & Hypertension \\
Htc & Pre- and postoperative hematocrit \\
ICU & Intensive care unit \\
LDL & Low-density lipoprotein \\
LIMA & Left internal mammarian artery \\
LMCA & Left main coronary artery \\
MI & Myocardial infarction \\
\hline
\end{tabular}

\section{INTRODUCTION}

Atherosclerotic coronary artery disease (CAD) is the leading cause of morbidity and mortality in the developed countries, and the World Health Organization estimate that it will be leading cause of death all over the world by the year $2020^{[1]}$. It primarily affects the 40 year and older population but younger males and females can also be affected ${ }^{[2]}$. In the autopsies of 760 accident, homicide or suicide victims aged between 15 and 34; it was founded that in 2\% of the 15-19 year old males group there were advanced atheromas in the coronary arteries as well as there were no coronary lesions in the same aged females group ${ }^{[3]}$. In the same study, $20 \%$ of the 30-34 year old males group and $8 \%$ of the same aged females group had advanced coronary artery lesions ${ }^{[3]}$. In the 20-24 year old male group there were advanced coronary lesions in about $2 \%$ of the patients, but not in the female group. In the 25-29 year old male and female groups, the percentage of advanced coronary artery lesions were nearly the same (between $2-3 \%)^{[3]}$.

Young patients who had suffered myocardial infarction (MI), usually have more than one risk factors related with CAD. In results of some studies, it is reported that $90-97 \%$ of the patients had one or more risk factors for atherosclerosis ${ }^{[2,4,5]}$. Smoking ${ }^{[2-7]}$, family member with $\mathrm{CAD}^{[2,5,7]}$, hypercholesterolemia ${ }^{[2,3,5-7]}$, diabetes mellitus (DM ${ }^{[2,4,5,7]}$, hypertension (HT) $)^{[2,3,5-7]}$, obesity ${ }^{[2,3,6,7]}$ and other risk factors such as oral contraceptives in young females, cocaine addiction, etc ${ }^{[8]}$ may act as etiological factors in younger patients for coronary atherosclerosis.

As the incidence of CAD in younger patients increases, the coronary artery bypass graft $(\mathrm{CABG})$ surgery practice increases in this population. It is known that $\mathrm{CABG}$ surgery can prolong the life time especially in patients with left main coronary artery (LMCA) or 3-vessel disease when compared to medical therapy ${ }^{[9]}$. There are many studies concerning the results of CABG surgery in younger patients and many different results are reported in these studies about the risk factors for CAD. In this retrospective study, we evaluated the pre and postoperative data of the CABG surgery in 45 year old patients and younger aged male and female patients and aimed to determine the effect of gender on these parameters.

\section{METHOD}

\section{Patient Selection}

In most of the studies, patients between 40 - 45 years of age are considered as "young"[2] so we decided to include the patients who were younger than 45 years in our study. A total of 324 patients were selected to be included to the study from the data pool of 5527 patients who underwent CABG surgery between April 12, 2004 and January 10, 2012 in Adana Numune Training and Research Hospital Fatma Kemal Timuçin Heart Center, Adana, Turkey. Off-pump CABG surgery, concomitant heart valve or aortic surgery, age over 45 years were criteria for exclusion.

\section{Patient groups}

Patients were divided into groups according to their gender. Group 1 consisted of 269 males (mean age 41.3) and Group 2 consisted of 55 females (mean age 41.6). All the patients were operated under standard cardiopulmonary bypass (CPB) circumstances. All the data of the following parameters of groups were compared: Smoking, diabetes mellitus, hypertension, chronic obstructive pulmonary disease (COPD), low-density lipoprotein (LDL) levels, body mass index (BMI), pre- and post-operative hematocrit (Htc), left internal mammarian artery (LIMA) graft utilization, the amount of blood product used, the length of intensive care unit (ICU) stay, aortic cross-clamping (ACC) and cardiopulmonary bypass time, inotropic agent administration, intra-aortic balloon pump (IABP) counter pulsation, preoperative ejection fraction (EF), postoperative drainage through chest tubes and mortality rates.

\section{Surgical procedure}

In the operating room, after electrocardiographically (ECG) and invasive blood pressure monitoring was set, general anesthesia protocol was followed. After median sternotomy and LIMA and saphenous vein graft harvesting, CPB was established with an ascending aortic and a single two stage right atrial cannula. After heparinization with bolus injection of $3 \mathrm{mg} / \mathrm{kg}$ of body weight heparin, cardiopulmonary bypass circuit was initiated with a roller pump and non-pulsatile flow technique. Moderate hemodilution (hematocrit value: 22 to 24\%) and mild hypothermia (nasopharyngeal temperature: $32^{\circ} \mathrm{C}$ ) were sustained during CPB. Pump flow rate during CPB was maintained at $2.4 \mathrm{l} / \mathrm{m}^{2} / \mathrm{min}$ and mean arterial blood pressure was sustained above $60 \mathrm{mmHg}$. A membrane oxygenator (Compactflo Evo, Dideco, Mirandola, Italy) was used for CPB. Pump prime was a volume of 1 liter of $0.9 \%$ sodium chloride solution. Ante grade $10 \mathrm{ml} / \mathrm{kg}$ blood cardioplegia solution was administered through the aortic root cannula. After completion 
of each distal coronary anastomosis, $250 \mathrm{ml}$ of cardioplegic solution was administered through the grafts. Ringer's lactate solution at $4^{\circ} \mathrm{C}$ was used for topical cooling of the heart. Left internal mammary artery grafts were reconstructed to the left anterior descending arteries (LAD) as the final anastomosis in all patients. Proximal anastomoses were implemented under partial aortic clamping.

\section{Preoperative data}

The mortality in the first post-operative 30-day period was used to compare the mortality rates of the groups. The total amount of hemorrhage through the mediastinal and thoracic drainage tubes until they were drawed was defined as mediastinal drainage. Re-operation for any reason (bleeding, cardiac tamponade, graft failure, etc) in the first postoperative 24 hour period was defined as postoperative revision. Other parameters were recorded as they were.

\section{Statistical Analysis}

All tests were performed using SPSS for Windows 13.0. Categorical values were expressed by numbers and percentages and the numerical values were expressed as mean \pm standart deviation. After normality tests were employed, Mann Whitney $\mathrm{U}$ test and chi-square $\left(\mathrm{x}^{2}\right)$ test were used to compare groups. A $P$ value less than 0.05 were accepted as significant.

\section{RESULTS}

The demographical data, risk factor distribution and co morbidities of the groups are shown in Table 1. Smoking rate was higher in Group 1, DM incidence and BMI were higher in Group 2 ( $P$ values $P=0.01 ; P=0.0001 ; P=0.04$ respectively). Age, HT and COPD incidence were not significantly different. There were no significant differences for the following data either: LDL levels, preoperative EF, Htc values, ventilator support duration, drainage through chest tubes, blood transfusion volumes, the length of ICU stay and length of hospital stay (Table 2).

Table 1. Demographic data of the groups and distribution of the risk factors.

\begin{tabular}{lccc}
\hline & Group 1 $(\mathrm{n}=269)$ & Group 2 $(\mathrm{n}=55)$ & $P$ value \\
\hline Age (mean) & $41.3 \pm 3.3$ & $41.6 \pm 3.8$ & 0.2 \\
BMI & $26.2 \pm 4.7$ & $27.7 \pm 5.1$ & 0.04 \\
Smoking & $161(59.9 \%)$ & $22(40 \%)$ & 0.01 \\
LDL & $117.5 \pm 44.2$ & $115.8 \pm 41.7$ & 0.912 \\
EF (\%) & $53.3 \pm 7.2$ & $52.7 \pm 8.1$ & 0.701 \\
DM & $59(22 \%)$ & $29(53 \%)$ & 0.0001 \\
HT & $50(19 \%)$ & $16(29 \%)$ & 0.098 \\
COPD & $11(4 \%)$ & $1(2 \%)$ & 0.698 \\
\hline
\end{tabular}

DM=Diabetes Mellitus; $E F=$ Ejection fraction; $H T=$ Hypertension; $C O P D=$ Chronic Obstructive Pulmonary Disease $; D L=$ Low Density Lipoprotein; $B M I=$ Body mass index
Graft counts in the groups were as follows (Group 1/ Group 2 respectively): One vessel 26/10 patients, two vessels $84 / 25$ patients, three vessels $126 / 17$ patients, four vessels $30 / 3$ patients and five vessels $3 / 0$ patients (Table 3 ). The ACC happened to be $37.7 \pm 15$ mins and CPB time was $67.5 \pm 23.6$ mins in Group 1 and they were $33.3 \pm 13$ mins and $60.5 \pm 22.5$ mins respectively in Group 2. The ACC and CPB time and graft counts per patient were significantly higher in Group $1(P=0.04 ; P=0.04 ; P=0.002)$ (Table 3$)$. The LIMA graft utilization rate was $86.4 \%$ in the study population. It was higher in Group 1 and it was statistically significant $(88.5 \%$ in Group 1; 76.4\% in Group 2; $P=0.03$ ) (Table 3).

Inotropic agent support was needed for weaning from CPB in $46 \%$ of the patients. The EuroSCORE values of the patients were between 0 and 3 . There was one patient that IABP support was needed for weaning from CPB in Group 1. No mortalities happened in either of the groups.

Table 2. Clinic data of the groups.

\begin{tabular}{lccc}
\hline & $\begin{array}{c}\text { Group 1 } \\
(\mathrm{n}=269)\end{array}$ & $\begin{array}{c}\text { Group 2 } \\
(\mathrm{n}=55)\end{array}$ & $P$ value \\
\hline Graft Count (mean) & $2.6 \pm 0.8$ & $2.2 \pm 0.8$ & 0.002 \\
Preoperative Hct & $42.7 \pm 4.5$ & $41.9 \pm 4.2$ & 0.255 \\
Postoperative Hct & $28.3 \pm 2.1$ & $28.3 \pm 2.2$ & 0.852 \\
Blood transfusion (Unit) & $0.9 \pm 1.1$ & $1.1 \pm 1.1$ & 0.319 \\
Inotropic support & $129(48 \%)$ & $20(36 \%)$ & 0.155 \\
Ventilatory support (hr) & $3.8 \pm 1.4$ & $3.8 \pm 1.7$ & 0.978 \\
Chest tube drainage (ml) & $443 \pm 174$ & $420 \pm 178$ & 0.378 \\
ICU stay (days) & $1.14 \pm 0.3$ & $1.18 \pm 0.3$ & 0.489 \\
In-hospital stay (days) & $4.3 \pm 0.4$ & $4.2 \pm 0.4$ & 0.600 \\
\hline
\end{tabular}

Hct=Hematocrit; $I C U=$ Intensive care unit

Table 3. Operative data of the groups.

\begin{tabular}{lcc}
\hline Graft Count & Group 1 $(\mathrm{n}=269)$ & Group 2 $(\mathrm{n}=55)$ \\
\hline One vessel & $26(10 \%)$ & $10(18 \%)$ \\
Two vessels & $84(31 \%)$ & $25(45 \%)$ \\
Three vessels & $126(47 \%)$ & $17(31 \%)$ \\
Four vessels & $30(11 \%)$ & $3(5 \%)$ \\
Five vessels & $3(1 \%)$ & 0 \\
ACC time (mins) & $37.7 \pm 15$ & $33.3 \pm 13.4$ \\
CPB time (mins) & $67.5 \pm 23.6$ & $60.5 \pm 22.5$ \\
IABP & 0 & $1(1.8 \%)$ \\
LIMA & $238(88 \%)$ & $42(76 \%)$ \\
\hline
\end{tabular}

$\overline{A C C}=$ Aortic cross-clamping; $C P B=$ Cardio-pulmonary bypass; IABP=Intra-aortic balloon pump; LIMA=Left internal mammarian artery

\section{DISCUSSION}

It is reported that sedentary life style, excessive consumption of fatty foods, smoking, HT, etc are more commonly seen in people with $\mathrm{CAD}^{[6]}$. These findings were confirmed in Framingham study and by observing the people with atherosclerotic 
diseases in younger ages. But it is also shown that advanced coronary artery disease may occur without the previous habits and risk factors ${ }^{[6]}$.

The coronary atherosclerosis is shown to be present in autopsy studies of the patients in their 20's and some studies report that about $19 \%$ of males in their early 30 's have advanced coronary artery atherosclerosis ( $>40 \%$ stenos). Smoking, HT and dislipidemia are very important factors for premature CAD in young patients ${ }^{[6]}$. Besides that smoking is shown to be the main risk factor ${ }^{[2,6,8]}$. Kannel et al. ${ }^{[8]}$ reported in Framingham study that smokers aged between 35 - 40 years have 3 times more relative risk of $\mathrm{CAD}$ according to non-smokers in the same age. Also the studies evaluating the results of younger age patient undergoing CABG surgeries showed high rates of smoking in their patient populations $s^{[7,9,10]}$. The smoking rate in our patient population was $56.5 \%$ and it was more common in males than females $(P=0.007)$.

In a study conducted in 1998, the smoking prevalence was in $62.8 \%$ of theTurkish male population and $24.3 \%$ in Turkish female population ${ }^{[11]}$. In our study, the smoking rate of males was similar to that data (59.9\% vs. $62.8 \%)$ but it was remarkably higher in our female patient group ( $40 \%$ vs. $24.3 \%)$.

Gu et al. ${ }^{[12]}$ reported in their study that the most common etiology of mortality in diabetic patients younger than 40 years of age was CAD. Diabetics have $2-4$ times higher risk of CAD according to non-diabetics ${ }^{[6]}$. It is not clear how the $\mathrm{CAD}$ progresses in young diabetic female patients despite the protective effect of estrogen ${ }^{[8]}$. Smoking and oral contraceptive administration together can increase mortality of CAD about 13.6 times $^{[13]}$. Truncal obesity and high BMI are independent risk factors of mortality of CAD in females ${ }^{[8]}$. The DM incidence and BMI were found to be significantly higher in female patients in relation to males in our study $(53 \% v s .22 \%$, $P=0.0001 ; 27.7 \%$ vs. $26.2 \% ; P=0.04$ respectively).

The results of CABG surgery are better in patients younger than 40 years. Five years survival rate is $92 \%$ and the 10 year survival rate is $86 \%$ but the same rates for the 65 years and older age population are $73 \%$ and $58 \%$, respectively ${ }^{[14]}$. Rocha et al. ${ }^{[15]}$ also reported that the in-hospital mortality of elderly patients was $8.9 \%$ in their study. In a meta-analyses Sá et al found no effect of gender, number of grafts and age on the outcomes ${ }^{[16]}$. The long term patency of internal mammarian artery (IMA) graft is better than saphenous vein graft so it is accepted to use IMA grafts for the LAD lesions in younger patients ${ }^{[17,18]}$. The utilization rate of LIMA graft is $86.4 \%$ in our study. It is significantly higher in Group 1 in relation to Group 2 (88.5\%; 76.4\% respectively; $P=0.03$ ).

Wagner et al. ${ }^{[19]}$ reported that they used LIMA grafts in all of the 126 patients under 40 years of age as well as 286 saphenous vein grafts ( 2.3 grafts per patient). Five of their patients needed IABP support and 1 patient needed left ventricle assist device. They reported their in-hospital mortality rate as $1.6 \%$ (2 patients) ${ }^{[17]}$. The graft count per patient in our study was 2.6 and 2.2 for Group 1 and Group 2 respectively. ACC and CPB duration, graft count per patient and LIMA graft utilization rates were higher in Group $1(P=0.002 ; P=0.04$; $P=0.04 ; P=0.03$ respectively). IABP support was needed for one patient and $46 \%$ of the patients needed inotropic agent support in our study. No mortality happened in either group.

\section{CONCLUSION}

Smoking appears to be the most important risk factor for both males and females under 45 years although DM and high BMI appear to be remarkable for the female population. We found that gender does not affect the early mortality rates in younger age population and postoperative period is shorter than for older age patients. We can say that to achieve the higher long term survival rates, at least one arterial bypass graft should be used and risk factors especially smoking, DM and BMI should strictly be kept under control.

\begin{tabular}{|ll|}
\hline Authors' & roles \& responsibilities \\
\hline HU & Medical records survey, research director \\
MA & Reference check, statistic \\
LA & Research design \\
PD & Language control, research design \\
ID & Reference search, Languaage check \\
İÖ & Medical records survey \\
\hline
\end{tabular}

\section{REFERENCES}

1. Reddy KS, Yusuf S. Emerging epidemic of cardiovascular disease in developing countries. Circulation. 1998;97(6):596-601.

2. Navas-Nacher EL, Colangelo L, Beam C, Greenland P. Risk factors for coronary heart disease in men 18 to 39 years of age. Ann Inter Med. 2001;134(6):433-9.

3. McGill HC Jr, McMahan CA, Zieske AW, Tracy RE, Malcom GT, Herderick EE, et al. Association of coronary heart disease risk factors with microscopic qualities of coronary atherosclerosis in youth. Circulation. 2000;102(4):374-9.

4. Chouhan L, Hajar HA, Pomposiello JC. Comparison of thrombolytic therapy for acute myocardial infarction in patients aged $<35$ and $>55$ years. Am J Cardiol. 1993;71(2):157-9.

5. Hoit BD, Gilpin EA, Henning H, Maisel AA, Dittrich H, Carlisle $\mathrm{J}$, et al. Myocardial infarction in young patients: an analysis by age subsets. Circulation. 1986;74(4):712-21.

6. Noeman A, Ahmad N, Azhar M. Coronary artery disease in young: Faulty life style or heredofamilial or both. Annals. 2007;13(2):162-4. 
7. Zehr KJ, Lee PC, Poston RS, Gillinov AM, Greene PS, Cameron DE. Two decades of coronary artery bypass graft surgery in young adults. Circulation. 1994;90(5 Pt 2):II133-9.

8. Klein LW, Nathan S. Coronary artery disease in young adults. J Am Coll Cardiol. 2003;41(4):529-31.

9. Tokmakoğlu H, Kandemir Ö, Farsak B, Günaydın S, Yorgancığlu $\mathrm{C}$, Zorlutuna Y. Coronary artery bypass surgery in young patients. Turkish J Thorac Cardiovasc Surg. 2002;10:1-4.

10. French JK, Scott DS, Whitlock RM, Nisbet HD, Vedder M, Kerr AR, et al. Late outcome after coronary artery bypass graft surgery in patients $<40$ years old. Circulation. 1995;92(9 Suppl):II14-9.

11. Şahin EM, Özer C, Çakmak H, Tunç Z, Taştan K, Can EN. Smoking status of medical students. Balkan Med J. 2007;24(3):209-12.

12. Gu K, Cowie CC, Harris MI. Mortality in adults with and without diabetes in a national cohort of the U.S. Population, 1971-1993. Diabetes Care. 1998;21(7):1138-45.

13. Tanis BC. Oral contraceptives and the risk of myocardial infarction. Eur Heart J. 2003;24(5):377-80.
14. Egred M, Viswanathan G, Davis GK. Myocardial infarction in young adults. Postgrad Med J. 2005;81(962):741-5.

15. Rocha AS, Pittella FJ, Lorenzo AR, Barzan V, Colafranceschi AS, Brito JO, et al. Age influences outcomes in 70-year or older patients undergoing isolated coronary artery bypass graft surgery. Rev Bras Cir Cardiovasc. 2012;27(1):45-51.

16. Sá MP, Ferraz PE, Escobar RR, Martins WN, Lustosa PC, Nunes Ede O, et al. Off-pump versus on-pump coronary artery bypass surgery: meta-analysis and meta-regression of 13,524 patients from randomized trials. Rev Bras Cir Cardiovasc. 2012;27(4):631-41.

17. Ng WK, Vedder M, Whitlock RM, Milsom FP, Nisbet HD, Smith WM, et al. Coronary revascularisation in young adults. Eur J Cardiothorac Surg. 1997;11(4):732-8.

18. Wu HY, Hueng GG, Lee GC, Lee SG, Tsai CS. Coronary artery bypass surgery in a 24 year-old man: A case report and reviews of literature. J Med Sci. 1999;20(3):157-63.

19. Wagner J, Ennker J, Hetzer R. Characteristics of patients younger than 40 years of age operated for coronary artery disease. Herz. 1996;21(3):183-91. 